\title{
Study of Clinical, Angiographic Profile and Outcome of Patients Undergoing Coronary Angioplasty of Left main Coronary Artery: MCVTC Experience.
}

\author{
Ratna Mani Gajurel, Raja Ram Khanal, Chandra Mani Poudel, Hemant Shrestha, Surya Devkota, \\ Sanjeev Thapa, Smriti Shakya.
}

Department of Cardiology, Manmohan Cardio Thoracic Vascular and Transplant Centre (MCVTC), Institute of Medicine, TUTH, Kathmandu, Nepal.

\section{Corresponding Author:}

Raja Ram Khanal

Department of Cardiology, Manmohan Cardio Thoracic Vascular and Transplant Centre (MCVTC), Institute of Medicine, TUTH, Kathmandu, Nepal.

E-mail: khanalr82@gmail.com

ORCID ID: https://orcid.org/0000-0002-4952-2307

Submitted date: $29^{\text {th }}$ November 2020

Accepted date: $8^{\text {th }}$ February 2021

Cite this article as: Gajurel R M, Khanal R R, Poudel C M. et al. Study of Clinical, Angiographic Profile and Outcome of Patients Undergoing Coronary Angioplasty of Left main Coronary Artery: MCVTC Experience. Nepalese Heart Journal 2021; Vol 18 (1): 19-24.

\section{Abstract}

Background and Aims: Coronary artery bypass graft is the treatment of choice for left main disease. However the results from several large multicenter trials have shown that the angioplasty of left main disease is an alternative treatment. The aim of this study was to assess the outcome of patients undergoing angioplasty of left main disease.

Methods: This prospective study was conducted at Manmohan cardiothoracic vascular and transplant center, Maharajgunj, Kathmandu, Nepal. Twenty-Five patients with a diagnosis of left main coronary artery disease who underwent coronary angioplasty were enrolled in the study. The cases were followed up and outcomes on follow up were assessed.

Results: Patients with left main disease enrolled in this study belonged to the age group of 51 to 77 years. The mean age of patients was $64.7 \pm 8.12$ with $68 \%$ (17) male and $32 \%$ (8) female. Among 25 patients 3 patients had single vessel disease, double vessel in 10 patients and triple vessel in 12 patients. Three patients (12\%) had previous history of percutaneous coronary intervention and $1(4 \%)$ had previous history of coronary artery bypass graft. All patients underwent successful procedure with unprotected left main stenting in 14 cases (56\%). There was few major and minor complications and no procedure related mortality and in hospital death.

Conclusion: Left main coronary angioplasty is a safe and alternative procedure to CABG with low incidence of major clinical events.

Keywords: Coronary Artery bypass Graft (CABG); PCI (Percutaneous Coronary Intervention); Unprotected Left main Coronary Artery (ULMCA).

DOI: https://orcid.org/10.3126/njh.v18i1.36774

\section{Introduction}

Left Main (LM) coronary artery disease incidence varies between 4 to $7 \%{ }^{1}$ It portends higher prognostic risk as a result of larger myocardial territory at risk. Patients with unprotected left main coronary artery disease treated medically has a 3-year mortality rate of $50 \% .{ }^{2,3}$ Coronary artery bypass graft (CABG) has been the therapy of choice for left main coronary artery disease for several decades. ${ }^{4}$ But the non inferior result of percutaneous coronary intervention
(PCI) in these patients have changed the scenario and have shown the beneficial use mainly in high surgical risk patients. Many recent studies have focused on the safety and efficacy of stenting of left main disease with similar complications as compared to CABG. ${ }^{5,6,7}$

The advances in PCI techniques and stent technology have allowed the evaluation of the role of PCI for LM disease with minimal complications.

(a) Nepalese Heart Journal. Nepalese Heart Journal retain copyright and works is simultaneously licensed under Creative Commons Attribution License CC - By 4.0 that allows others to share the work with an acknowledge of the work's authorship and initial publication in this journal 


\section{Methods}

From 2018 January to 2019 December over two years period at Manmohan cardiothoracic Vascular and Transplant center (MCVTC), a total of 25 patients diagnosed as LM coronary artery disease who refused for $\mathrm{CABG}$ were enrolled in the study. A significant stenosis was defined as an LM coronary artery narrowing of $\geq 50 \% .{ }^{1}$ Both protected and unprotected LM were enrolled in the study. Unprotected left main stenosis was defined as a significant narrowing of the left main coronary artery without visible flow through collaterals or bypass grafts to the left anterior descending or left circumflex artery. ${ }^{8}$

The angiographic data were analyzed with SYNTAX (Synergy between PCI with TAXUSTM and Cardiac Surgery) score and classified as low (0-22), intermediate (23-32), and high $(\geq 33))^{9,10}$ The inclusion criteria of the study were high surgical risk for which surgeon refused for $\mathrm{CABG}$ and patients preference for PCI. Procedural success was defined as a residual intraluminal narrowing of $<20 \%$ obtained by coronary angiography without major cardiac procedural complications.

All the patients were followed-up clinically. Coronary angiography was not performed if the patients had no clinical presentation of myocardial ischemia or staged PCI done for non-LM lesions.

\section{Results}

During the period, a total of 25 patients had undergone LM coronary angioplasty. The mean age of the patients was $64.7 \pm 8.12$ years with male predominance. The clinical characteristics of the study group are shown in Table 1 .

\section{Procedure}

In all patients, the vessel was accessed via the femoral artery. Angioplasty was elective in 18 patients and urgent in the remaining 7 patients. In 20 patients $(80 \%)$, the lesions were predilated using a conventional balloon catheter and in 5 patients $(20 \%)$, the stent was implanted directly. The median diameter and length of the stents were $3.6 \pm 0.4 \mathrm{~mm}$ and $20.2 \pm 6.4 \mathrm{~mm}$, respectively. During the procedure intra-aortic balloon pump (IABP) was used in 2 patients and PCI was successful in all patients (Table 2). For distal LM lesion, provisional stenting from LM to left anterior descending artery (LAD) or left circumflex artery (LCX) with wire protection to LAD or LCX was done and in few patients DK Crush technique was done for bifurcation lesion. For ostial and mid shaft lesion, stenting from ostium to mid shaft was done.

After angioplasty all patients were given dual antiplatelet agents (Aspirin and clopidogrel) and were followed up clinically.

At the time of diagnostic angiography, 10 patients $(40 \%)$ were known to have stable angina, $8(32 \%)$ had Unstable angina (USA)/ Non ST elevation myocardial infarction (NSTEMI) and 7 (28\%) had ST elevation myocardial infarction (STEMI). The mean left ventricular ejection fraction in these patients was $45 \pm 11.2 \%$ with 8 patients (32\%) having ejection fraction $\leq 30 \%$ (Table1).

Among 25 patients, 3 patients had single vessel disease, double vessel in 10 patients and triple vessel in 12 patients. Three patients $(12 \%)$ had previous history of PCI and $1(4 \%)$ had previous history of CABG. Unprotected left main was in 14 patients (56\%) (Table 2). All patients received drug-eluting stents without Intravascular ultrasound (IVUS) guidance.

Table 1: Clinical characteristics of patients who received left main coronary artery stent.

\begin{tabular}{|c|c|c|}
\hline $\begin{array}{l}\text { Patients } \\
\text { Characteristics }\end{array}$ & Number & Percentage (\%) \\
\hline Age (years) & \multicolumn{2}{|c|}{ Mean: $64.7 \pm 8.12$ SD Range: $51-77$} \\
\hline \multicolumn{3}{|l|}{ Sex } \\
\hline Male & 17 & 68 \\
\hline Female & 8 & 32 \\
\hline Family History of Coronary Artery Disease & 2 & 8 \\
\hline HCV Positive & 1 & 4 \\
\hline History of Smoking & 8 & 32 \\
\hline Diabetes & 8 & 32 \\
\hline Hypertension & 10 & 40 \\
\hline Dyslipidemia & 3 & 12 \\
\hline Chronic Kidney Disease & 3 & 12 \\
\hline \multicolumn{3}{|l|}{ Clinical Presentation } \\
\hline Stable Angina & 10 & 40 \\
\hline Unstable Angina & 5 & 20 \\
\hline NSTEMI & 3 & 12 \\
\hline STEMI & 7 & 28 \\
\hline
\end{tabular}

LV Systolic Function (EF) Mean \pm SD

$45 \pm 11.2 \%$ 
Table 2: Lesion and procedural characteristics.

\begin{tabular}{|c|c|c|}
\hline $\begin{array}{l}\text { Patients } \\
\text { Characteristics }\end{array}$ & Number & Percentage $(\%)$ \\
\hline \multicolumn{3}{|l|}{ Coronary Artery Disease } \\
\hline Single Vessel Disease & 3 & 12 \\
\hline Double Vessel Disease & 10 & 40 \\
\hline Triple Vessel Disease & 12 & 48 \\
\hline Only Left Main Disease & 0 & 0 \\
\hline Unprotected LM & 14 & 56 \\
\hline Protected LM & 11 & 44 \\
\hline Previous History of PCI & 3 & 12 \\
\hline Previous History of CABG & 1 & 4 \\
\hline Use of IABP & 2 & 8 \\
\hline \multicolumn{3}{|l|}{ Syntax Score } \\
\hline Low: $0-22$ & 4 & 16 \\
\hline Intermediate: $23-32$ & 7 & 28 \\
\hline High $: \geq 33$ & 14 & 56 \\
\hline Mean \pm SD & $35.2 \pm 11.5$ & \\
\hline \multicolumn{3}{|l|}{ Coronary Angioplasty } \\
\hline LM to LAD: & 16 & 64 \\
\hline LM to LCX: & 8 & 32 \\
\hline Only LM & 1 & 4 \\
\hline Multi Vessel PCI: & 16 & 64 \\
\hline Procedure Success & 25 & 100 \\
\hline \multicolumn{3}{|l|}{ Target Lesion } \\
\hline Ostial LM & 5 & 20 \\
\hline Mid LM & 3 & 12 \\
\hline Distal LM & 17 & 68 \\
\hline \multicolumn{3}{|l|}{ Procedural Characteristics } \\
\hline Single Stent & 6 & 24 \\
\hline Bare Metal Stent (BMS) & 0 & 0 \\
\hline Drug Eluting Stent (DES) & 25 & 100 \\
\hline Direct Stenting & 5 & 20 \\
\hline Total Stent Length & $30 \mathrm{~mm}$ & \\
\hline IVUS Guided PCI & 0 & \\
\hline
\end{tabular}


During procedure till hospital stay few major and minor complications occurred. The minor complications were vasovagal attack in two patients $(8 \%)$, hematoma at the punctured site in one patient $(4 \%)$ and contrast allergy in one patient $(4 \%)$. The major complications occurred in 5 patients $(20 \%)$ which were acute pulmonary edema in two patients $(8 \%)$, one patients $(4 \%)$ developed cardiogenic shock, which subsequently recovered and two patients $(8 \%)$ developed arrhythmia after the procedure. However there was no procedure related mortality with no in hospital death and no emergency CABG was required (Table 3 ).

Table 3: In hospital outcome.

\begin{tabular}{|lll|}
\hline Outcome & Number & $\begin{array}{l}\text { Percentage } \\
(\%)\end{array}$ \\
\hline $\begin{array}{l}\text { Periprocedural/Post } \\
\text { Procedural MI }\end{array}$ & 0 & 0 \\
\hline $\begin{array}{l}\text { Stent Thrombosis } \\
\text { Emergency CABG }\end{array}$ & 0 & 0 \\
\hline Acute Pulmonary Edema & 0 & 0 \\
\hline Cardiogenic Shock & 2 & 8 \\
\hline Stroke & 1 & 4 \\
\hline Cardiac Tamponade & 0 & 0 \\
\hline Arrhythmia & 0 & 0 \\
\hline Ventricular Tachycardia & 2 & 8 \\
\hline Atrial Fibrillation & 1 & 4 \\
\hline $\begin{array}{l}\text { Death (Procedure Related/ In } \\
\text { Hospital/Cardiac/Noncardiac) }\end{array}$ & 0 & 4 \\
\hline
\end{tabular}

\section{Follow Up}

All patients were followed up clinically for a mean follow up of 11.4 \pm 5.6 months (range 3-24 months) after the procedure by undergoing detailed questioning in a cardiology out patient department and by a phone call. Among 25 patients, $96 \%$ were under close follow up and 1 lost to follow up with even no contact on phone. During follow-up, 6 patients $(25 \%)$ presented with major clinical events with both Acute Coronary Syndrome (ACS) and other cardiac cause (Table 4). One patient died on follow up on readmission due to refractory heart failure. There was no repeat need of revascularization either PCI or CABG in any patients.
Table 4: Clinical outcome on follow up (N:24)

\begin{tabular}{lll} 
Outcome & Number & $\begin{array}{l}\text { Percentage } \\
(\%)\end{array}$ \\
\hline $\begin{array}{l}\text { Readmission for Acute } \\
\text { Coronary Syndrome }\end{array}$ & 3 & 12 \\
\hline USA/NSTEMI & 3 & 12 \\
\hline STEMI & 0 & 0 \\
\hline Repeat CAG & 3 & 12 \\
\hline Stent Thrombosis & 1 (Non LM Lesion) & 4 \\
\hline $\begin{array}{l}\text { Readmission for other } \\
\text { Cardiac Cause }\end{array}$ & 3 & 12 \\
\hline Heart Failure & 2 & 8 \\
\hline Ventricular Tachycardia & 1 & 4 \\
\hline Readmission for Stroke & 0 & 0 \\
\hline Repeat Revascularization & & 0 \\
\hline PCI & 0 & 4 \\
\hline CABG & 0 & 0 \\
\hline Death & 1 & \\
\hline
\end{tabular}

\section{Discussion}

Although CABG remains the standard therapy for LM coronary artery disease, several studies have demonstrated the clinical outcomes of LM revascularization. ${ }^{11,12}$ Advances in CABG and PCI techniques assessed in recent randomized trials showed that PCI for LMCA disease is a safe option with similar long-term survival rates to $\mathrm{CABG}$ surgery particularly in those with low and intermediate anatomic risk. ${ }^{13,14} \mathrm{~A}$ large amount of data from observational registries to clinical randomized trials supports the feasibility, efficacy and safety of stenting compared with CABG for the treatment of LM coronary artery disease. ${ }^{15-20}$

The mean age of patients in our study was $64.7 \pm 8.12$ years with male predominance. The major risk factors for CAD in our study were diabetes and hypertension (32\% and $40 \%$ respectively). In the study conducted by Marti $\mathrm{V}$ et al hypertension and diabetes were 57 and $52 \%$ respectively. ${ }^{21}$ The majority of patients in our study presented with stable angina and on angiography most of the patients had Triple Vessel Disease (TVD) (48\%). In the study conducted by Hsiao-Yang Cheng et $\mathrm{al}^{22}$ the majority of patients presented with USA/NSTEMI and most of the patients had TVD (44\%) on coronary angiography.

There were 3 Chronic Kidney Disease (CKD) patients (12\%) with TVD and LM disease who had undergone successful coronary 
angioplasty in our study. This was similar to the study conducted by Hsiao-Yang Cheng et $\mathrm{al}^{22}$ where $15 \%$ were CKD patients. Whereas in another study conducted by Marti $\mathrm{V}$ et $\mathrm{al}^{21} 5 \%$ cases were of CKD.

During angioplasty most of the patients had undergone LM to LAD stenting $(64 \%)$ with only LM stenting in 1 patients $(4 \%)$. The procedure was successful in all patients $(100 \%)$ which was similar $(100 \%)$ to various other conducted studies. ${ }^{23-26}$

In another study conducted by W.T. Ruifrok et $\mathrm{al}^{27}$ the PCI was successful in $98 \%$ cases. During the procedure, IABP was used in 2 patients $(8 \%)$. There was no procedure related mortality and emergency CABG done in our study. This was similar to the study conducted by Hsiao-Yang Cheng et $\mathrm{al}^{22}$ where $9.9 \%$ had use of IABP and no procedure related mortality and emergency CABG needed. In another study conducted by W.T. Ruifrok et $\mathrm{al}^{27}$ procedure related mortality was in 1 patients $(0.8 \%)$ and need of emergency CABG was in 1 patients $(0.8 \%)$. PCI of LMCA can be done even without surgical back up facility and many centers are doing it with good short term and long-term results.

Five patients $(20 \%)$ had major complications during and after procedure which comprised pulmonary edema, cardiogenic shock and arrhythmia but there was no in hospital death after procedure on first admission. In the study conducted over 38 patients by Marti V et $\mathrm{al}^{21} 10 \%$ had major complications and in hospital mortality was $15 \%$. In another study conducted by W.T. Ruifrok et a ${ }^{27}$ there was $7(5.9 \%)$ in hospital death (among 118 cases) primarily related to cardiac cause. Similarly in another study conducted on 200 patients by A. Gagnor et al ${ }^{28}$ the major complications occurred in $44 \%$ with in hospital mortality of $11 \%$.

In our study during follow up (mean:11.4 \pm 5.6 months) 6 patients $(25 \%)$ had major clinical events in the form of ACS and other cardiac cause but no patients developed stroke even on follow up period. There was 1 cardiac death (4\%) by the end of follow up period. In the study conducted by W.T. Ruifrok et $\mathrm{al}^{27}$ the major cardiovascular events at the end of follow up period (average: 8 months) was 36\% with cardiac death in $6.8 \%$ cases and total death of $25 \%$ (both cardiac and non cardiac) at the end of follow up period. In another study conducted in 70 patients by Hsiao-Yang Cheng et al ${ }^{22}$ within 1 year follow up $37 \%$ cases were hospitalized due to major cardiovascular events and all cause mortality rate was $28 \%$ (cardiac $11 \%$, non cardiac $17 \%$ ).

\section{Study Limitations}

This was a non-randomized prospective study with a small sample size. There was no use of IVUS in our study due to unavailability of IVUS machine in our center. Due to small sample size, this findings could not be fully generalized to all other patients, so a large randomized study is recommended for further confirmation of best revascularization strategy for significant LM stenosis.

\section{Conclusion}

PCI of LM coronary artery is a safe and effective procedure with low incidence of major cardiac events. Patient selection is crucial and must be based on proper heart team discussion.

\section{Conflict of Interest: None Acknowledgement: None}

\section{References}

1. Conley MJ, Ely RL, Kisslo JO, et al. The prognostic spectrum of left main stenosis. Circulation.1978 May;57(5):947-52. https://doi.org/10.1161/01.CIR.57.5.947
2. Taylor HA, Deumite NJ, Chaitman BR, et al. Asymptomatic left main coronary artery disease in the Coronary Artery Surgery Study(CASS)registry. Circulation.1989Jun;79(6):1171-9. https://doi.org/10.1161/01.CIR.79.6.1171

3. Cohen MV, Gorlin RI. Main left coronary artery disease. Clinical experience from 1964-1974. Circulation.1975Aug;52(2):275-85. https://doi.org/10.1161/01.CIR.52.2.275

4. Caracciolo EA, Davis KB, Sopko G. Comparison of surgical and medical group survival in patients with left main coronary artery disease. Long-term CASS experience. Circulation. 1995;91:2325-34.

https://doi.org/10.1161/01.CIR.91.9.2325

5. E. Meliga, H. M. Garcia-Garcia, M. Valgimigli. Longest available clinical outcomes after drugeluting stent implantation for unprotected left main coronary artery disease. The DELFT (Drug Eluting stent for LeFT main) registry. Journal of theAmericanCollegeofCardiology.2008;51(23):2212-19. https://doi.org/10.1016/j.jacc.2008.03.020

6. P. E. Buszman, P. P. Buszman, R. S. Kiesz, et al. Early and longterm results of unprotected left main coronary artery stenting. The LE MANS (Left Main Coronary Artery Stenting) registry. Journal of the American College of Cardiology.2009; 54(16):1500-11.

https://doi.org/10.1016/j.jacc.2009.07.007

7. S.J. Park, Y.H. Kim, B.K. Lee, et al. Sirolimus-eluting stent implantation for unprotected leftmain coronary artery stenosis: comparison with bare metal stent implantation. Journal of the American College of Cardiology.2005; 45 (3):351-356. https://doi.org/10.1016/j.jacc.2004.10.039

8. Smith SC, Dove JT, Jacobs AK, et al. ACC/AHA guidelines for percutaneous coronary intervention (revision of the 1993 PTCA guidelines) A report of the American College of Cardiology/American Heart Association Task Force on practice guidelines (Committee to revise the 1993 guidelines for percutaneous transluminal coronary angioplasty) endorsed by the Society for Cardiac Angiography and Interventions. Journal of the American College of Cardiology. 2001 Jun $15 ; 37(8): 2215-39$. doi: https://doi.org/10.1016/s0735-1097(01)01344-4

9. Sianos G, Morel MA, Kappetein AP, et al. The SYNTAX Score: an angiographic tool grading the complexity of coronary artery disease. EuroInterv. 2005;1:219-27.

10. SYNTAX Score calculator: http://ir-nwr.ru/calculators/ syntaxscore/frameset.htm.

11. ACCF/SCAI/STS/AATS/AHA/ASNC 2009 Appropriateness Criteria for Coronary Revascularization. A Report of the American College of Cardiology Foundation Appropriateness Criteria Task Force, Society for Cardiovascular Angiography and Interventions, Society of Thoracic Surgeons, American Association for Thoracic Surgery, American Heart association, 
and the American Society of Nuclear Cardiology. Endorsed by the American Society of Echocardiography, the Heart Failure Society of America, and the Society of Cardiovascular Computed Tomography. J Am Coll Cardiol. 2009; 53:530-53.

12. Huang HC, Kao HL, Wu XM, et al. Long-term prognosis in ethnic Chinese patients with unprotected left main coronary artery disease. Clin Res Cardiol. 2010; 99:437-43.

https://doi.org/10.1007/s00392-010-0139-5

13. Morice MC, Serruys PW, Kappetein AP, et al. Five-year outcomes in patients with left main disease treated with either percutaneous coronary intervention or coronary artery bypass grafting in the synergy between percutaneous coronary intervention with taxus and cardiac surgery trial. Circulation. 2014;129:2388-2394.

https://doi.org/10.1161/CIRCULATIONAHA.113.006689

14. Stone GW, Sabik JF, Serruys PW, et al. Everolimus-eluting stents or bypass surgery for left main coronary artery disease. N Engl J Med. 2016; 375:2223-2235. https://doi.org/10.1056/NEJMoa1610227

15. Park DW, Seung KB, Kim YH, et al. Long-term safety and efficacy of stenting versus coronary artery bypass grafting for unprotected left main coronary artery disease: 5 -year results from the MAIN-COMPARE (Revascularization for Unprotected Left Main Coronary Artery Stenosis: Comparison of Percutaneous Coronary Angioplasty Versus Surgical Revascularization) registry. Journal of the American College of Cardiology. 2010 Jul 6;56(2):117-24. https://doi.org/10.1016/j.jacc.2010.03.097

16. Chieffo A, Meliga E, Latib A, et al. Drug-eluting stent for left main coronary artery disease. The DELTA registry: A multicenter registry evaluating percutaneous coronary intervention versus coronary artery bypass grafting for unprotected left main treatment. JACCCardiovascInterv.2012;5:718-27. https://doi.org/10.1016/j.jcin.2012.03.022

17. Buszman PE, Kiesz SR, Bochenek A, et al. Acute and late outcomes of unprotected left main stenting in comparison with surgical revasculization. J Am Coll Cardiol 2008;51:538-45. https://doi.org/10.1016/j.jacc.2007.09.054

18. Chieffo A, Morici N, Maisano F, et al. Percutaneous treatment with drug-eluting stent implantation versus bypass surgery for unprotected left main stenosis. A single-centerexperience. Circulation.2006;113:2542-7. https://doi.org/10.1161/CIRCULATIONAHA.105.595694

19. Kappetein AP, Head SJ, Morice MC, et al. Treatment of complex coronary artery disease in patients with diabetes: 5 -year results comparing outcomes of bypass surgery and percutaneous coronary intervention in the SYNTAX trial. Euro J Cardio-thoracic Surgery. 2013;43:1006-13. https://doi.org/10.1093/ejcts/ezt017

20. Part SJ, Kim YH, Part DW, et al. Randomized trial of stents versus bypass surgery for left main coronary artery disease. N Engl J Med. 2011;364:1718-27. https://doi.org/10.1056/NEJMoa1100452

21. Martí V, Planas F, Cotes C, et al. Augé. Immediate and LongTerm Outcome After Angioplasty with Stenting of the Left Main Coronary Artery. Rev Esp Cardiol. 2004;57(11):102934 , https://doi.org/10.1016/S1885-5857(06)60188-6

22. Cheng HY, Wang KT, Lin WH, et al. Percutaneous Coronary Intervention for Left Main Coronary Artery Disease_A Single Hospital Experience without On-Site Cardiac Surgery Cardiol Sin. 2015;31:267-279.

23. Park SJ, Park SW, Hong MK, et al. Stenting of unprotected left main coronary stenoses: immediate and late outcomes. J Am Coll Cardiol. 1998;31:37-42. https://doi.org/10.1016/S0735-1097(97)00425-7

24. López JJ, Ho KKL, Stoler RC, et al. Percutaneous treatment of protected and unprotected left main coronary stenoses with new devices: immediate angiographic results and intermediate -term follow-up. J Am Coll Cardiol. 1997;29:345-52. https://doi.org/10.1016/S0735-1097(96)00488-3

25. Silvestri M, Barragan P, Sainsous J, et al. Unprotected LCA stenting: Immediate and medium term outcomes of 140 elective procedures. JAmCollCardiol.2000;35:1543-50 https://doi.org/10.1016/S0735-1097(00)00588-X

26. Black A, Cortina R, Bossi I, et al. Unprotected LCA stenting. Correlates of midterm survival and impact of patient selection. J Am Coll Cardiol. 2001;37:832-8. https://doi.org/10.1016/S0735-1097(00)01176-1

27. Ruifrok WT, Jessurun GA, Tio RA, Zijlstra F. Angioplasty of the left main coronary artery: Mid-term follow-up at University Medical Centre Groningen. Netherlands Heart Journal. 2005 Oct;13(10):348.

28. Gagnor A, Tomassini F, Cerrato E et al. Unprotected LeftMain Coronary Angioplasty in the Elderly in a High Volume Catheterization Centre without On-Site Surgery Facilities: Immediate and Medium Term Outcome-The Old-Placet Registry Advances in Vascular Medicine. 2015; Article ID 751293: 1-7. http://dx.doi.org/10.1155/2015/751293 